\title{
Methodology and Application of Safety Evaluation of Reinforced Concrete Girder Bridges during Earthquakes
}

\author{
Guangjun Sun $\mathbb{D}^{1},{ }^{1,2}$ Zhijie Yuan $\left(\mathbb{D},{ }^{3}\right.$ Bingyan $W u\left(\mathbb{D},{ }^{1,2}\right.$ and Fu Zhao ${ }^{1,2}$ \\ ${ }^{1}$ College of Civil Engineering, Nanjing Tech University, Nanjing 211816, China \\ ${ }^{2}$ Institute of Engineering Mechanics, Nanjing Tech University, Nanjing 211816, China \\ ${ }^{3}$ Key Laboratory of Concrete and Prestressed Concrete Structures of Ministry of Education, Southeast University, Nanjing, \\ Jiangsu 211189, China \\ Correspondence should be addressed to Zhijie Yuan; 15150998570@163.com
}

Received 23 February 2021; Revised 12 July 2021; Accepted 14 December 2021; Published 5 January 2022

Academic Editor: Annamaria Pau

Copyright (c) 2022 Guangjun Sun et al. This is an open access article distributed under the Creative Commons Attribution License, which permits unrestricted use, distribution, and reproduction in any medium, provided the original work is properly cited.

\begin{abstract}
The actual earthquake resistance performance and the seismic damage state of bridges during future earthquakes are important issues that need to be resolved. Using an expressway reinforced concrete (RC) girder bridge in a high seismic intensity area of China as the research object, the damage correlation between different structural components of the bridge is analyzed, and the key components that determine the structural safety state of the bridge are determined. Then, the safety evaluation indexes of the bridge pier and bearing are researched, and a two-stage seismic safety evaluation methodology for RC girder bridges is proposed. The first stage is a rapid and general evaluation using empirical statistical methods, and the second stage is a precise evaluation obtained by calculating the damage index of the components. Subsequently, the seismic damage prediction matrix is presented. Considering the modification of the bridge span number, service life, and skew angle, a seismic safety evaluation from a typical single bridge to a group of bridges of the same type is implemented. Finally, an actual expressway bridge in China is presented as a numerical example to illustrate the application of the method. The research results show that damage to the key components, including bearings, piers, and abutments, is the deciding factor of the bridge damage state. The seismic damage states of piers and bearings can be conveniently assessed according to the pier top displacement angle and bearing shear deformation during earthquakes. According to the suggested standard of RC girder bridge seismic damage, the seismic safety evaluation of the whole bridge structure can be obtained using the seismic safety evaluation of individual key components of the bridge structure. According to the evaluation results of individual bridges and considering the modification of influencing factors, an earthquake performance evaluation of a group of bridges of the same type can be obtained. The two-stage seismic safety evaluation methodology proposed in this study is effective and efficient.
\end{abstract}

\section{Introduction}

Once the bridge is damaged during an earthquake, it will inevitably lead to a decline or even suspension of the overall function of the transportation system. Not only is the direct economic loss huge, but the damage will also seriously affect postearthquake rescue work. Indirect loss and social and political impacts are immeasurable. On the one hand, after an earthquake, bridges and other transportation infrastructures play an extremely important role in earthquake emergency responses. The actual safety of bridges after an earthquake, the state of traffic capacity, whether they have service functions, and how to assess the magnitude of the failure are necessary questions to be answered. On the other hand, if service bridges known to have poor seismic performance or defects are strengthened to improve their seismic capacity before an earthquake, this will effectively reduce their potential seismic damage and failure in the event of an earthquake. The evaluation of the actual safety of bridge structures after an earthquake is required in order to reduce the loss resulting from earthquake disasters, make emergency relief plans, and carry out relief actions.

Current research on the seismic resistance of bridge structures is very mature [1-4]. Since the 1960 s and the 
1970s, the United States and Japan have conducted seismic evaluations of highway bridges in service, and early evaluations were mainly based on empirical statistical methods [5]. After the 1989 Loma Prieta earthquake in the United States, substantial progress has been made in the study of seismic performance evaluation of bridges, and a seismic performance evaluation method based on priority evaluation and the pushover method was proposed [6-8]. After the 1994 Northridge earthquake in the United States and the 1995 Southern Hyogo earthquake in Japan, earthquake engineering scholars seriously evaluated the seismic design method based on the bearing capacity of the bridges and proposed a performance-based seismic design method. The performance/displacement-based seismic design and evaluation method of bridges has become the focus of scholars worldwide [9].

Research on seismic safety assessments of existing bridges in China was relatively recent. The early work was mainly based on empirical statistical methods [10] and code checking methods. Based on the statistical analysis of earthquake damage of more than 100 highway bridges in the Tangshan, Haicheng, and Tonghai earthquakes, Meizhen [11] established a set of frameworks and procedures for seismic safety assessment of existing bridges and provided empirical formulas for earthquake damage prediction of bridges. The code checking method requires first the calculation of the seismic load of the main components of the bridge according to the relevant provisions in the "Code for seismic design of Highway Engineering (TJT004-89)" in China. Then, the seismic load effect is combined with the dead load effect to obtain the total internal load of the bridge structural components. The load is then compared with the ultimate load of the bridge structural components to obtain the seismic damage level of the bridge. After 2000, some domestic scholars introduced the pushover method to evaluate seismic safety and predict the seismic damage of bridges [12-14].

From the research results at home and abroad [15-19], the commonly used bridge seismic damage prediction methods currently include empirical statistical methods, code check methods, structural analysis methods, neural network prediction methods, and fuzzy comprehensive evaluation methods. The empirical statistical methods can determine the possible damage level of bridges in future earthquakes without complex calculations and are convenient to use, especially for the earthquake damage prediction of a large number of bridges in a certain area or city. The disadvantage is that these methods are based on a large amount of statistical data and a rich experience in bridge seismic damage making it difficult to choose the influencing factors and their interactions. If some of the statistical data or the bridge history is missing, the calculation error may be relatively large. The code checking method is suitable for earthquake damage prediction of bridges on good foundations or soft foundations with relatively complete antiliquefaction measures. The calculation formula of the code checking method is consistent with the current code formula, which is easy for engineering and technical personnel to master and apply. However, owing to the lack of statistical data, the real strength of materials is usually replaced by the nominal strength, resulting in errors. Owing to its high technical requirements, heavy calculation workload, and complicated processing of results, the structural analysis method is not suitable for engineering practice and group prediction.

This study considered the typical reinforced concrete (RC) girder bridge as the research object. This type of bridge design is widely used in expressways in China, such as in simply supported girder bridges and continuous girder bridges. The key structural components of the bridge to be used in the safety evaluation were determined from the damage correlation analysis. The safety evaluation index of the key components was studied. Subsequently, a two-stage seismic safety evaluation method for RC girder bridges was established, and an earthquake damage prediction matrix was developed. Finally, by modifying the factors affecting the seismic performance of the bridge, the transformation from the seismic safety evaluation of a typical single bridge to a group of bridges of the same type was realized.

\section{Determination of Key Evaluation Components of RC Girder Bridge}

From the seismic damage of bridges in previous earthquakes, it has been learned that the damage state of the substructure is the key factor in determining the overall safety state of bridge structures. As the main ductile energy dissipation component of the substructure, the damage degree of the pier directly determines the safety state of the bridge structure. However, the bridge structure is also affected by the damage degree of the bearing, abutment, and other components. Evaluating the damage condition of a bridge structure only from a single component can lead to incorrect evaluation results.

Based on the seismic damage data of 112 beam bridges in the Haicheng earthquake (1975), Tangshan earthquake (1976), Turki Izmit earthquake (1999), Lijiang earthquake in Yunnan (1996), Jiji earthquake in Taiwan (1999), Loma Prieta earthquake (1989), Beiling earthquake (1994), and Wenchuan earthquake (2008) [20], the damage correlation coefficients of different bridge components were calculated according to formula (1), and the results are presented in Table 1.

$$
\rho_{X Y}=\frac{\operatorname{COV}(X, Y)}{\sqrt{D(X) D(Y)}},
$$

where $\rho_{X Y}$ is the correlation coefficient of variables $X$ and $Y$, $\mathrm{COV}(\cdot)$ is the covariance, and $D(\cdot)$ is the standard deviation.

Table 1 shows that the bearing damage, pier damage, and abutment damage are highly correlated with other component damage, which is consistent with the research results reported in the literature [21]. The structural forms of the abutment and pier of expressway bridges are relatively consistent; most of them utilize pile column (three-column) abutments, which have higher structural safety than piers. In addition, although some of the earthquake damage is caused by pile foundation damage, piers and bearings are more 
TABLE 1: Seismic damage correlation coefficient of bridge components.

\begin{tabular}{lcccccccc}
\hline Destruction types & Bearing & Pier & Girder displacement & Abutment & Foundation & Unseating & Superstructure & Collision \\
\hline Bearing & 1 & 0.907 & 0.958 & 0.933 & 0.761 & 0.972 & -0.264 & 0.932 \\
Pier & 0.907 & 1 & 0.989 & 0.998 & 0.941 & 0.855 & -0.186 \\
Girder displacement & 0.958 & 0.989 & 1 & 0.995 & 0.909 & 0.924 & -0.175 \\
Abutment & 0.933 & 0.998 & 0.995 & 1 & 0.920 & 0.880 & -0.216 \\
Foundation & 0.761 & 0.941 & 0.909 & 0.920 & 1 & 0.760 & 0.119 & 0.938 \\
Unseating & 0.972 & 0.855 & 0.924 & 0.880 & 0.760 & 1 & -0.046 \\
Superstructure & -0.264 & -0.186 & -0.175 & -0.216 & 0.119 & -0.046 & 0.979 \\
Collision & 0.932 & 0.889 & 0.938 & 0.901 & 0.859 & 0.979 & 0.098 & 0.098 \\
\hline
\end{tabular}

Note. Collision mainly refers to the collision between adjacent main girders of the RC girder bridge during earthquakes.

critical bridge structural components. Based on the above factors, in this study, we selected piers and bearings as the key components of the bridge structure to be used in the bridge safety evaluation.

\section{Seismic Safety Evaluation Indexes of RC Girder Bridge}

3.1. Safety Evaluation Index of the Bridge Pier. The damage degree of the bridge pier is directly related to the rotation displacement of its plastic hinge section, that is, the displacement of the pier top. It is a simple and practical method to use the deformation as the seismic performance design and evaluation index. Performing the seismic design and evaluation directly based on the displacement of the pier top can realize the idea of performance-based seismic design. The plastic rotation angle and displacement of the pier top were clearly defined [22].

As a type of dimensionless deformation, the displacement angle of the pier top is widely used in the design codes of New Zealand, Japan, and the United States. The displacement angle at the top of the pier reflects the comparative relationship between the displacement at the top of the pier and the height of the pier. Under the action of earthquakes, the maximum displacement response of the pier top can be obtained directly by a relatively simple method (such as the response spectrum method), which avoids complex nonlinear calculations. In addition, the displacement angle of the pier top is in close agreement with the current "Guidelines for seismic design of highway bridges" in China [22], and the corresponding displacement of the pier top can be obtained by simple conversion.

In this study, the displacement angle of the pier top was selected as the safety evaluation index of the pier.

$$
D=\frac{u}{H}
$$

where $u$ is the displacement response of the top of the pier under a specific earthquake, and $H$ is the height of the pier.

The mechanisms of bending and shear failures are different. Therefore, it is difficult to use the same index to measure both types of failure. Furthermore, shear failure is a brittle type of failure, so it is of little significance to use the index to describe it. Therefore, in this study, we only investigated bending failure, which is more common in earthquake damage.
Based on a large number of quasistatic test data of RC piers collected by the University of California, Berkeley [23], the test data of RC piers conducted by Japan's Kawashima ichiko earthquake engineering laboratory and the test data of some domestic scholars, 93 cylindrical RC piers with bending failure were selected as statistical samples, and the statistical analysis and probability distribution fitting of the pier top displacement angle under different damage states were carried out. The statistical parameters of the selected test components are listed in Table 2. The upper and lower confidence limits were selected based on a $95 \%$ confidence interval. Table 2 shows that the test components selected in this study are similar to those of typical piers in China, and the longitudinal reinforcement ratio and volume stirrup ratio meet the requirements of the "Guidelines for seismic design of highway bridges" in China [22].

Four damage states of piers with slight damage (II), moderate damage (III), severe damage (IV), and damage (V) are defined by steel yield, concrete cracking, concrete spalling, and steel buckling, respectively $[24,25]$.

To achieve a better goodness of fit, a lognormal distribution was used to fit the pier top displacement angles in damage states II and V, and a normal distribution was used to fit the pier top displacement angles in damage states III and IV. Based on the probability analysis of the pier top displacement angle under different damage conditions, the minimum pier top displacement angle limit with a $95 \%$ probability confidence was determined as the benchmark allowable value. Considering the actual situation of the project and the rationality of the value, the seismic safety evaluation indexes of concrete piers corresponding to each damage state were obtained, as presented in Table 3.

The failure test results of concrete piers are affected by many parameters, such as the concrete strength, reinforcement ratio, and axial compression ratio. Through the single factor analysis of the test results of the pier top displacement angle under various damage states, it was found that with an increase in the longitudinal reinforcement ratio, the allowable displacement angle of the pier top under various damage states has an increasing trend, but the trend is mild and the degree of influence is small; however, with an increase in the material strength and volume reinforcement ratio, the allowable displacement angle of the pier top shows a decreasing trend, the trend is more moderate, and the degree of influence decreases. The allowable displacement angle of the pier top decreases with an increasing axial 
TABLe 2: Statistical parameters of experimental components.

\begin{tabular}{lcccc}
\hline & Average & Variance & Minimum value & Maximum value \\
\hline Concrete strength $(\mathrm{MPa})$ & 35.3 & 7.83 & 23.1 & 60.6 \\
Longitudinal reinforcement ratio (\%) & 2.29 & 1.05 & 0.53 & 5.57 \\
Volumetric stirrup ratio (\%) & 1.01 & 0.50 & 0.13 & 3.04 \\
Aspect ratio & 4.64 & 1.75 & 1.99 & 10 \\
Axial load level & 0.14 & 0.13 & 0 & 0.7 \\
\hline
\end{tabular}

TABle 3: Safety evaluation index of bridge pier.

\begin{tabular}{lccccc}
\hline Damage state & $\begin{array}{c}\text { I Basically } \\
\text { intact }\end{array}$ & II Slight damage & III Medium damage & IV Severe damage & V destruction \\
\hline $\begin{array}{l}\text { State description } \\
\text { Allowable }\end{array}$ & Crack & $\begin{array}{c}\text { Longitudinal } \\
\text { reinforcement yield } \\
\text { displacement angle }\end{array}$ & $\begin{array}{c}\text { Local institutions } \\
\text { began to form }\end{array}$ & $\begin{array}{c}\text { Local institutions is } \\
\text { completely formed }\end{array}$ & $\begin{array}{c}\text { Strength degradation } \\
\text { D }\end{array}$ \\
\hline
\end{tabular}

compression ratio, and its degree of influence cannot be ignored. Therefore, in this study, the allowable displacement angle of the pier top under different damage states presented in Table 3 was modified by the axial compression ratio. The polynomial fitting results of the influence of the axial compression ratio on the allowable displacement angle of the pier top under different damage states are shown in Figure 1.

Figure 1 shows that with an increase in the axial compression ratio of the pier, the displacement angles of the pier top in different damage states show a decreasing trend, and the more serious the damage state of the pier, the more significant the influence of the axial compression ratio on the displacement angle. Considering that the reference value of the allowable displacement angle has a 95\% probability confidence, the correction should not be too large; otherwise, the result is too conservative and does not have engineering applicability.

By fitting the mean value of the pier top displacement angle and the coefficient of the modified axial compression ratio, it was found that they basically met the linear relationship. Therefore, the modified coefficient corresponding to the mean value of the pier top displacement angle under different damage states in the statistical data was used as the reference value, and the modified coefficient corresponding to the standard value of the allowable displacement angle with a $95 \%$ probability confidence was derived. The allowable displacement angle was then corrected. The proposed correction formula for the allowable displacement angle axial compression ratio can be expressed as follows:

$$
D_{m}=D_{k}-\frac{D_{k}}{\bar{D}} K(N-0.14)
$$

where $D_{m}$ is the allowable displacement angle after considering the axial compression ratio correction, $K$ is the influence of the axial compression ratio on the allowable displacement angle of the pier top under different damage states, that is, the slope of the linear relationship between the displacement angle of the pier top and the axial compression ratio obtained by fitting, as shown in Figure 1. The

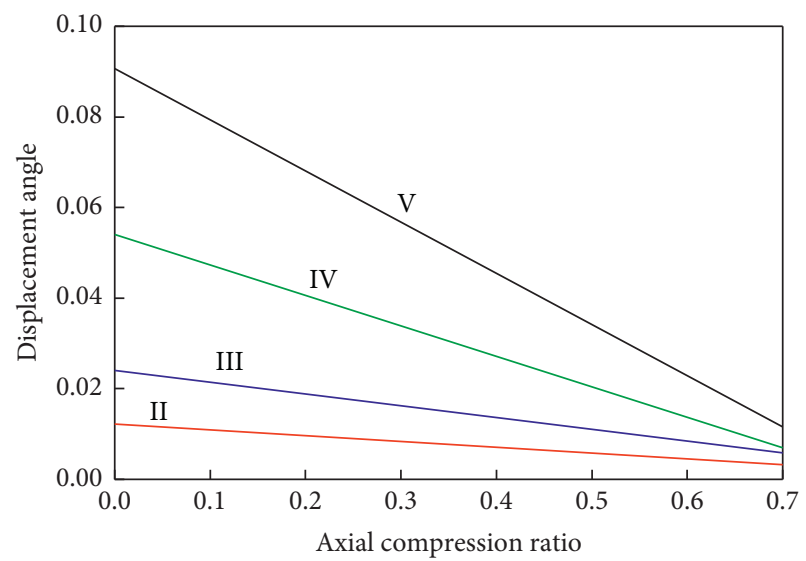

FIgURE 1: Influence of the axial compression ratio on the allowable displacement angle of the pier top.

corresponding values of damage states II-V were 0.0114 , $0.0287,0.0640$, and 0.1195 , respectively. $D_{k}$ is the reference value of the allowable displacement angle with a $95 \%$ probability confidence, as listed in Table $3, \bar{D}$ is the test mean value of the allowable displacement angle, $N$ is the axial compression ratio, and 0.14 is the test mean value of the axial compression ratio.

3.2. Safety Evaluation Index of Bridge Bearing. Few studies have been conducted on the safety evaluation of bearings, mainly from the physical quantities of shear deformation, shear force, and shear displacement, to evaluate the damage state of bearings. In this study, the allowable shear deformation was selected as the safety evaluation index of the evaluation support [26, 27], and the values are listed in Table 4.

$$
\gamma=\frac{x_{0}}{\sum t}
$$

where $\gamma$ is the shear deformation of the support, $X_{0}$ is the horizontal shear displacement of the rubber bearing, and $\Sigma t$ is the total thickness of the rubber layer of the bearing. 
TABLE 4: Safety evaluation index of bearing.

\begin{tabular}{lccccc}
\hline Damage state & Basically intact & Slight damage & Medium damage & Severe damage & Destruction \\
\hline Shearing deformation & $<100 \%$ & $>100 \%$ & $>150 \%$ & $>200 \%$ & $>250 \%$ \\
\hline
\end{tabular}

\section{Two-Stage Evaluation Method of RC Girder Bridge}

4.1. First Stage Evaluation. The first stage is the rapid assessment. According to the specific information of the bridge, an empirical statistical method is selected to provide the seismic damage assessment results under different seismic intensity conditions that may be encountered in the future. The main purpose of the first-stage evaluation is to perform an overall screening to determine the priority to be assigned to the bridge in a second-stage evaluation.

In reference [28], the seismic damage of 89 girder bridges in the Tangshan and Wenchuan earthquakes was taken as a sample to perform parameter fitting. Considering that there is no linear relationship between the general seismic damage degree and the seismic intensity, site type, and other factors, the nonlinear equation expression method proposed by Meizhen [11] was referenced, and the relationship between seismic liquefaction, slope instability, seismic intensity, site type, and other factors was considered. The original empirical statistical method was modified accordingly to the site conditions. The calculation formula given in reference [28] is as follows:

$$
Y_{i}=c_{0} c_{6} \prod_{j=1}^{n} \prod_{k=1}^{r_{j}} c_{j k}^{x_{i j k}}
$$

where $Y_{i}$ is the seismic damage index of the $i$-th bridge in the sample, $i$ is the number of statistical samples, $n$ is the number of influencing factors, $r_{j}$ is the classification number of the $j$ th influencing factor, $c_{0}$ and $c_{j k}$ are influence coefficients, $c_{6}$ is the influence coefficient of slope instability and site liquefaction on earthquake damage, and $x_{i j k}$ is the input value of a certain seismic damage factor of the $i$-th bridge, and its value is defined as 1 or 0 according to whether factor $j$ of the $i$-th bridge belongs to the $k$-th category. The seismic damage grade and corresponding seismic damage index interval are listed in Table 5.

We verified that the results of equation (5) were in good agreement with the actual results, as presented in Table 5.

4.2. Second Stage Evaluation. In the second stage, a bridge with serious earthquake damage or a bridge that was identified in the first stage as requiring special attention was selected, and finite element modelling was established. The structural response was analyzed according to the response spectrum or nonlinear time history method. The damage state (basically intact, slight damage, moderate damage, serious damage, or destruction) of key components was evaluated according to the seismic response of the structure. The overall damage condition of the bridge structure was determined from the damage condition of the key bridge structural components. The results of the seismic damage assessment of the bridge under different seismic intensity conditions that may be encountered in the future, the seismic damage prediction matrix, are presented in Table 6. The values in the matrix must be determined according to the evaluation results for specific bridges.

The second stage of evaluation is a complex process. To infer the damage state of the entire bridge system from the seismic damage state of each key component, it is necessary to determine the joint probability distribution of each component to reach the limit state. This can only be achieved through large-scale numerical simulation analysis. In this study, according to the proposed standard for seismic damage classification of girder bridges and the description of the failure state of each seismic damage level $[20,28]$, the evaluation of the seismic safety of bridge structures from the damage state of key components was realized, as presented in Table 7.

In addition, to determine the damage to the bridge structure based on the results of the prediction of the damage state of key components, a conversion formula from component damage to structural damage was adopted. The specific conversion formula can be expressed as follows:

$D_{\text {System }}=\left\{\begin{array}{l}\operatorname{int}\left(0.75 D_{\text {pier }}+0.25 D_{\text {bearing }}\right) D_{\text {pier }}, D_{\text {bearing }}<5, \\ 5 D_{\text {pier }} \text { or } D_{\text {bearing }}=5,\end{array}\right.$

where "int" is to round down to the nearest integer and $D$ is the damage state of the bridge structure or bridge piers and bearing members. When $D$ is equal to 1 , it is essentially intact. When $D$ is equal to two, it represents slight damage. When $D$ is equal to three, it represents medium damage. When $D$ is equal to four, it represents severe damage. When $D$ is equal to five, it indicates destruction.

\section{Group Prediction Modification of RC Girder Bridge}

When the empirical statistical method is used to evaluate the seismic safety of bridges, the subjectivity is strong, and the prediction accuracy is relatively poor. When the time history analysis method, response spectrum method, and other numerical analysis methods are used, the amount of calculation is large, and the results are only applicable for the prediction of the safety of a single bridge. To efficiently complete the seismic safety assessment of a group of bridges of the same type, a correction method was adopted in this study. The basic idea of this method is to analyze the seismic response of a bridge in a group of bridges of the same type and obtain the seismic response of other bridges of the same type by correction. To ensure the reliability of the correction results, the correction coefficient was obtained by 
TABle 5: Seismic damage index.

\begin{tabular}{|c|c|c|c|c|c|}
\hline Earthquake damage grade & Basically intact & Slight damage & Medium damage & Severe damage & Destruction \\
\hline Actual earthquake damage rate & $19 / 89$ & $18 / 89$ & $25 / 89$ & $9 / 89$ & $18 / 89$ \\
\hline Predicted earthquake damage rate & $19 / 89$ & $17 / 89$ & $27 / 89$ & $8 / 89$ & $18 / 89$ \\
\hline Seismic damage index $Y$ & $Y \leq 1.39$ & $1.39<Y \leq 2.04$ & $2.04<Y \leq 3.87$ & $3.87<Y \leq 4.82$ & $Y>4.82$ \\
\hline
\end{tabular}

TABle 6: Seismic damage prediction matrix.

\begin{tabular}{|c|c|c|c|c|c|c|}
\hline \multirow{3}{*}{ Earthquake damage grade } & \multicolumn{6}{|c|}{ Earthquake intensity } \\
\hline & \multicolumn{2}{|c|}{7} & \multicolumn{2}{|c|}{8} & \multicolumn{2}{|c|}{9} \\
\hline & E1 & E2 & E1 & $\mathrm{E} 2$ & E1 & E2 \\
\hline $\begin{array}{l}\text { Basically intact } \\
\text { Slight damage } \\
\text { Medium damage } \\
\text { Severe damage } \\
\text { Destruction }\end{array}$ & & & & & & \\
\hline
\end{tabular}

Note. The values in the matrix are 0 or 1 , according to the evaluation results.

TABle 7: Description of bridge damage at different levels.

\begin{tabular}{|c|c|c|}
\hline Damage grade & $\begin{array}{l}\text { Damage } \\
\text { degree }\end{array}$ & Destruction description \\
\hline Basically intact & $\begin{array}{l}\text { Most serious } \\
\text { Slightest }\end{array}$ & $\begin{array}{l}10 \% \text { of nonload-bearing components were damaged } \\
\text { No damage }\end{array}$ \\
\hline Slight damage & $\begin{array}{l}\text { Most serious } \\
\text { Slightest }\end{array}$ & $\begin{array}{l}50 \% \text { of the piers were damaged in grade I, } 10 \% \text { of the piers were damaged in grade II, } 10 \% \text { of the supports } \\
\text { were damaged, and } 50 \% \text { of the nonload-bearing members were damaged } \\
10 \% \text { of the piers were damaged in grade I and } 10 \% \text { of the nonload-bearing members were damaged }\end{array}$ \\
\hline \multirow{2}{*}{$\begin{array}{l}\text { Medium } \\
\text { damage }\end{array}$} & Most serious & $\begin{array}{l}50 \% \text { of the piers were damaged in grade II, } 10 \% \text { of the piers were damaged in grade III, } 10 \% \text { of the } \\
\text { supports were damaged, and all the nonload-bearing members were damaged }\end{array}$ \\
\hline & Slightest & $\begin{array}{c}10 \% \text { of the piers were damaged, } 10 \% \text { of the bearings were damaged, and } 50 \% \text { of the nonload-bearing } \\
\text { members were damaged }\end{array}$ \\
\hline \multirow{2}{*}{ Severe damage } & Most serious & $\begin{array}{l}80 \% \text { of the piers were damaged in grade III, } 10 \% \text { of the piers were damaged in grade IV, all the bearings } \\
\text { were destroyed, and the bridge deck was cracked, or } 10 \% \text { of the girders had fallen }\end{array}$ \\
\hline & Slightest & $\begin{array}{l}50 \% \text { of the piers were damaged in grade III and } 50 \% \text { of the bearings were damaged, the girders were } \\
\text { displaced and the bridge deck was cracked }\end{array}$ \\
\hline & Most serious & All the bridge piers and nonload-bearing components were completely destroyed \\
\hline Destruction & Slightest & $\begin{array}{c}40 \% \text { of the piers were damaged in grade IV }, 10 \% \text { of the piers were damaged in grade III and the nonload- } \\
\text { bearing components were almost completely destroyed }\end{array}$ \\
\hline
\end{tabular}

performing a large number of numerical simulations and statistical analyses.

In bridges with the same structure type, the bridge span number, service life, skew angle, span, and pier height will affect the damage state of a specific bridge. By considering different correction factors, damage state prediction from a typical single bridge to a group of bridges can be realized.

According to the research results of reference [29], the influence of the bridge span on the vulnerability of bridge structures is small, and the modification of the span influence is not considered in this study. In addition, the pier height of expressway bridges in high-intensity areas in China is less than $10 \mathrm{~m}$. According to the research results of reference [30], the influence of the pier height difference on the bridge damage state was not considered in this study. This study considers the influence of the span number, service life, and skew angle on the damage state of concrete bridges.
5.1. Span Number Correction. In general, the greater the number of bridge spans, the higher the damage probability of the bridge structure under earthquakes. Taking the average displacement angle of each pier top as the analysis index and keeping other parameters unchanged, a large number of numerical calculations were carried out for the displacement angle of the pier top of bridges with different span numbers under different intensities. The influence of the bridge span number on the displacement angle of the pier top is shown in Figure 2.

As shown in Figure 2, when the number of spans is nine or less, the influence of the number of spans on the displacement angle of the pier top is significant. When the number of bridge spans is more than nine, the change in the pier top displacement angle tends to be stable, and the changing trend of the pier top displacement angle is basically the same under different intensities. 


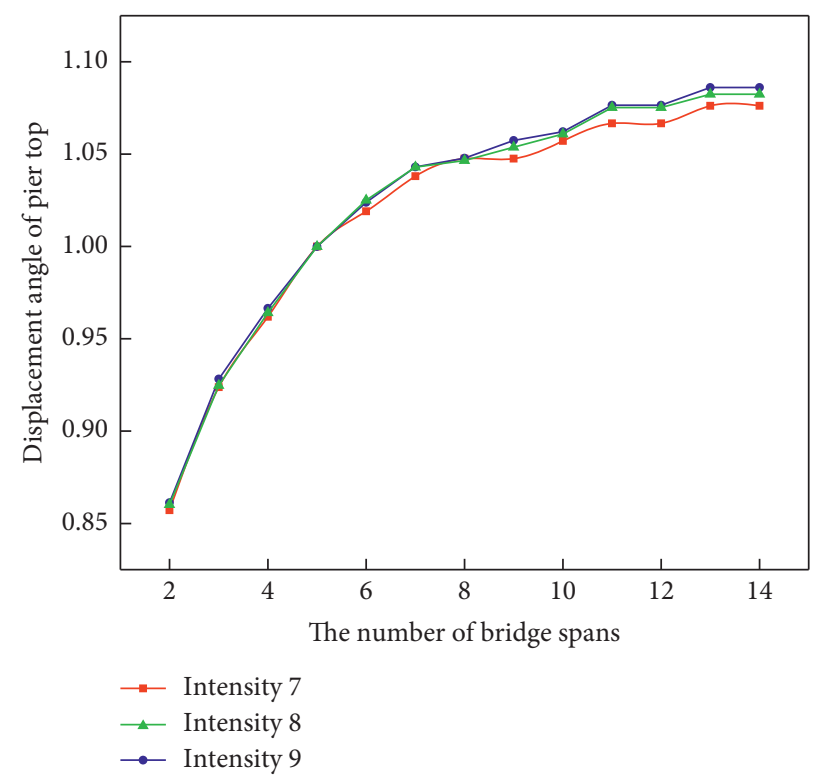

FIGURE 2: Influence of span number on displacement angle of bridge pier top.

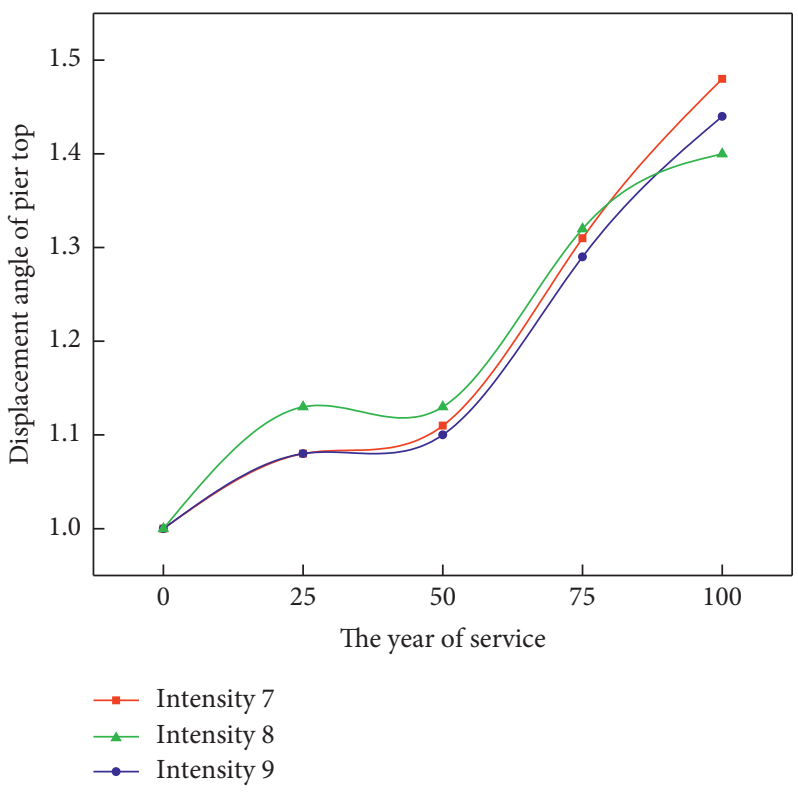

FIGURE 3: Influence of service life on displacement angle of bridge pier top.

Considering that most expressway bridges in high-intensity areas of China have more than five spans, in this study, we selected the pier top displacement angle of fivespan bridges as the standard value. By fitting the mean value of the curve shown in Figure 2, the correction coefficient of the pier top displacement angle under different spans $C_{n}$ can be obtained as follows:

$$
C_{n}=0.11 \ln (n)+0.81 .
$$

Considering that span is a discrete variable, the suggested value of $C_{n}$ is obtained according to equation (7), as shown in the following equation:

$$
C_{n}= \begin{cases}0.9, & n<4, \\ 1.0, & 4 \leq n<9, \\ 1.1, & n>9 .\end{cases}
$$

5.2. Service Life Correction. An increase in service life will inevitably have a negative impact on the seismic performance of bridge structures. To consider the service life correction to the seismic safety assessment results of bridges, in this study, we mainly investigated the aging of reinforced 


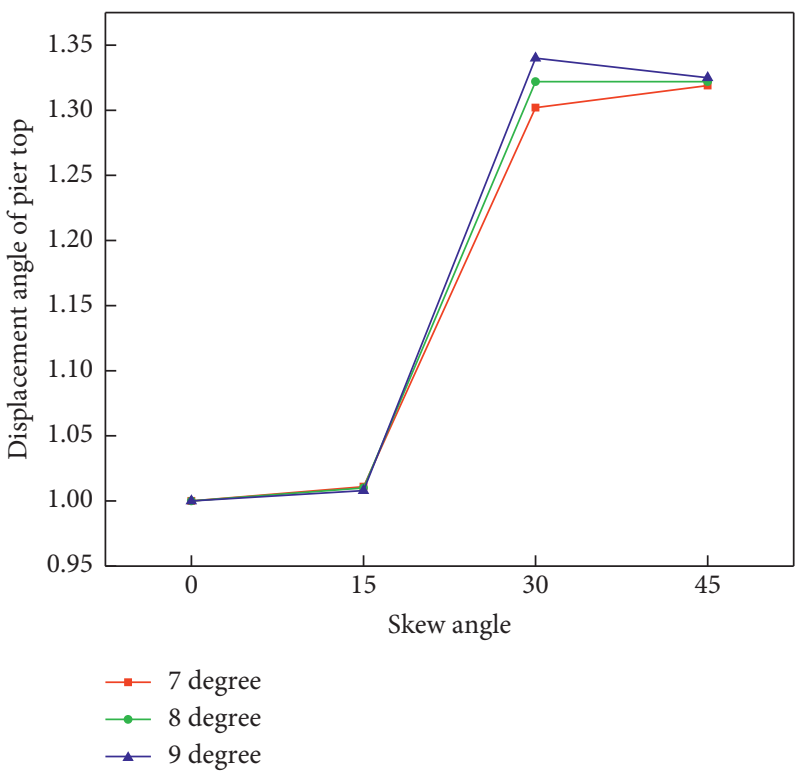

FIGURE 4: Influence of skew angle on displacement angle of bridge pier top.

concrete materials that affect the seismic performance of bridges.

Using the aging model of the RC material in reference [30], taking the pier top displacement angle of the new bridge as the standard value and keeping the other parameters unchanged, a large number of numerical calculations were carried out for the pier top displacement angles of bridges with service lives of $25,50,75$, and 100 years under different earthquake intensities; the influence of the service life on the pier top displacement angle is shown in Figure 3.

Figure 3 shows that the longer the service life is, the higher the damage probability of the bridge under earthquake action is. When the service life is 50 years or less, the influence of the service life on the displacement angle of the pier top is relatively stable. However, when the service life is more than 50 years, the change in the pier top displacement angle is very significant, and the changing trend of the pier top displacement angle is basically the same under different intensities.

By fitting the mean value of the curve shown in Figure 3, the correction coefficient of the service life $C_{t}$ can be obtained as follows:

$$
C_{t}=1+0.00145 t+2.9257 \times 10^{-5} \times t^{2},
$$

where $t$ is the service life.

5.3. Skew Angle Correction. A method similar to the above correction was adopted for the correction of the skew angle. Taking the pier top displacement angle of a straight girder bridge as the standard value and keeping the other parameters unchanged, a large number of numerical calculations were performed for the pier displacement angles of bridges with skew angles of $15^{\circ}, 30^{\circ}$, and $45^{\circ}$ under different intensities. The influence of the skew angle on the pier top displacement angle is shown in Figure 4.
Figure 4 shows that the larger the skew angle is, the higher the damage probability of the bridge under earthquake action is. When the skew angle is between 0 and $15^{\circ}$, or when the skew angle is greater than $30^{\circ}$, the influence of the skew angle on the displacement angle of the pier top is relatively stable. When the skew angle is $15^{\circ} \sim 30^{\circ}$, the changing trend of the displacement angle of the pier top is basically the same under different intensities.

The correction coefficient of the skew angle $C_{a}$ can be obtained by fitting the mean value of the curve shown in Figure 4 .

$$
C_{a}= \begin{cases}1+0.00567 \theta, & \theta \leq 15^{\circ}, \\ 1.085+0.00206(\theta-15), & 15^{\circ} \leq \theta \leq 30^{\circ}, \\ 1.3, & \theta>30^{\circ},\end{cases}
$$

where the $\theta$ is skew angle.

\section{Case Application}

6.1. Bridge Overview. A 6-span expressway RC girder bridge in Jiangsu Province of China is shown in Figure 5. The single span of the bridge is $13 \mathrm{~m}$, and the total length of the bridge is $81.96 \mathrm{~m}$. The superstructure is a $12.96 \mathrm{~m}$ wide concrete hollow slab girder. Piers No. 1 and No. 7 of the substructure are three-column piers, and the other piers are doublecolumn piers. Tie beams were set at the top of piers No. 4 and No. 5 with a diameter of $1.0 \mathrm{~m}$. The site type of the bridge is class II, and the site characteristic period is $0.35 \mathrm{~s}$.

6.2. First Stage Evaluation. The seismic intensity, superstructure form, pier height, span number, site type, bearing type, and liquefaction effect were selected as the influencing factors of seismic damage. According to equation (5), the improved bridge seismic capacity evaluation method based on empirical statistics was used to evaluate the case bridge. 

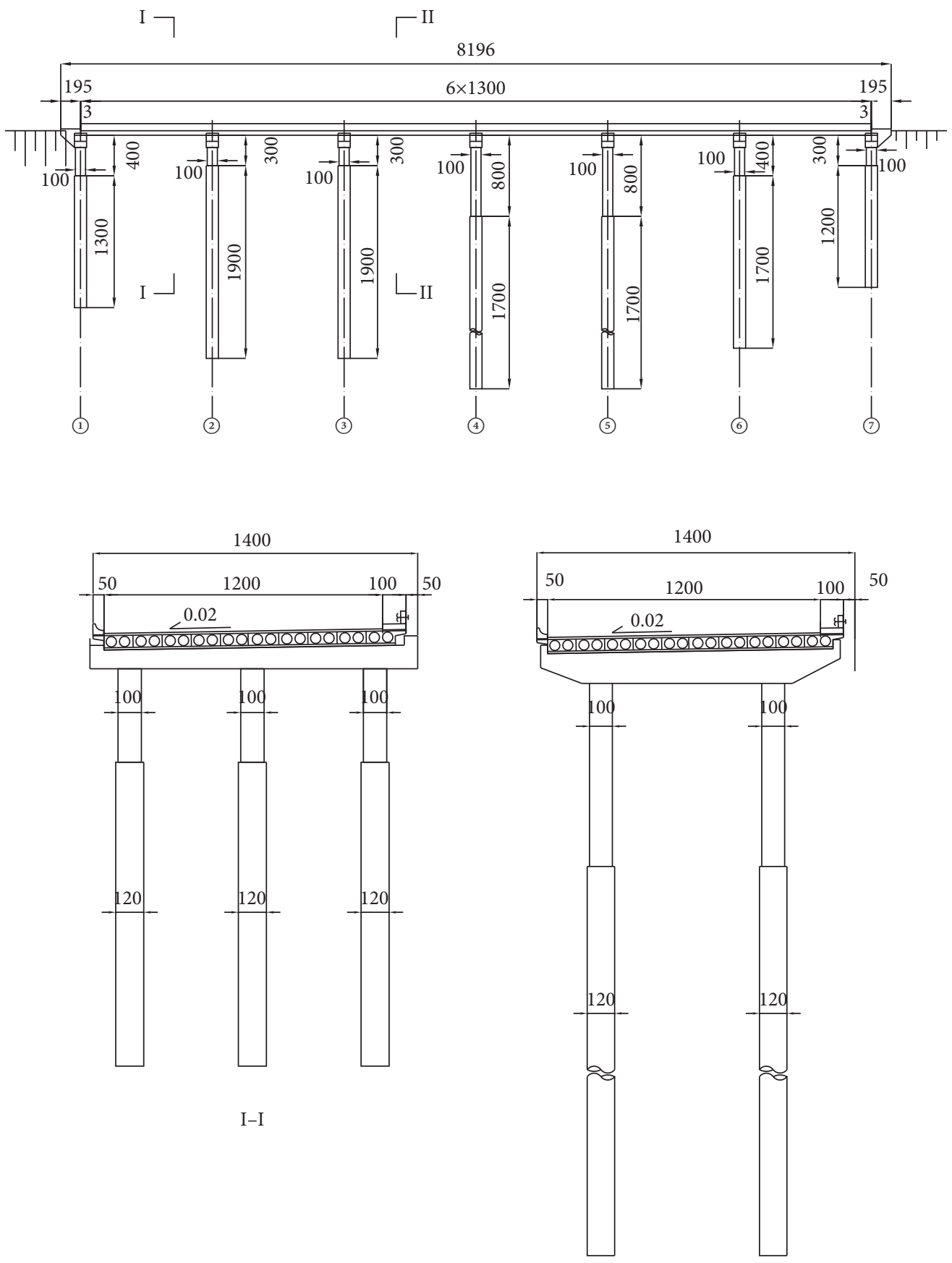

II-II

Figure 5: Layout of case bridge.

The influencing factors of seismic damage are listed in Table 8, and the evaluation results are presented in Table 9.

6.3. Second Stage Evaluation. Midas/civil 2013 software was used to establish the spatial finite element model of the bridge. The superstructure of the bridge is a simply supported concrete hollow slab beam that is simulated by a beam element. The pier, cap beam, and pile foundation of the substructure were also simulated by the beam element. The bearing was simulated by an elastic connection. The pile foundation simulation considers the interaction between the pile and soil, and the interaction was simulated by a spring. The spring stiffness was determined according to the " $m$ value method" in the "Code for design of foundation and foundation of highway bridge and culvert." A finite element model of the bridge is shown in Figure 6. 
TABLE 8: Influence factors of seismic damage evaluation.

\begin{tabular}{|c|c|c|c|c|c|c|c|c|c|}
\hline $\begin{array}{l}\text { Seismic } \\
\text { intensity }\end{array}$ & $\begin{array}{l}\text { Site } \\
\text { type }\end{array}$ & Superstructure & $\begin{array}{c}\text { Span } \\
\text { number }\end{array}$ & $\begin{array}{l}\text { Span- } \\
\text { length } \\
(\mathrm{m})\end{array}$ & $\begin{array}{l}\text { Pier } \\
\text { height } \\
(\mathrm{m})\end{array}$ & $\begin{array}{c}\text { Abutment } \\
\text { material }\end{array}$ & Basis type & $\begin{array}{l}\text { Bearing } \\
\text { type }\end{array}$ & Liquefaction impact \\
\hline VII $\sim \mathrm{IX}$ & II & $\begin{array}{l}\text { Simply supported } \\
\text { girder }\end{array}$ & 6 & 13 & 6.7 & $\mathrm{RC}$ & $\begin{array}{c}\text { Pile } \\
\text { foundation }\end{array}$ & $\begin{array}{l}\text { Rubber } \\
\text { bearing }\end{array}$ & IX degree \\
\hline
\end{tabular}

TABLE 9: $1^{\text {st }}$-stage evaluation results.

\begin{tabular}{lcc}
\hline Seismic fortification intensity & Scoring result & Evaluation result \\
\hline VII & 1.68 & Minor damage \\
VIII & 2.52 & Moderate damage \\
IX & 5.75 & Destruction
\end{tabular}

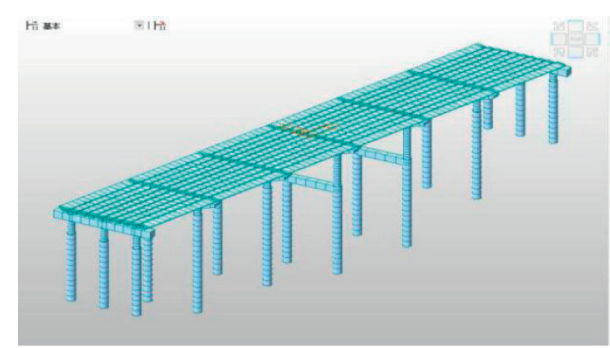

FIgURE 6: Bridge finite element model.

According to the "Guidelines for seismic design of highway bridges" in China, the response spectrum method was used to analyze the structural response with 7, 8, and 9 earthquake intensities, respectively. The earthquake input mode is E1 earthquake: longitudinal + transverse, E2 earthquake: longitudinal + transverse + vertical. The first 20 modes were selected for the combination. The SRSS method was used for the E1 earthquake, and the CQC method was used for the E2 earthquake.

The results of the pier top displacement angle response and bearing shear deformation response under different seismic intensities were calculated, and the damage states of the pier and bearing were evaluated according to the pier top displacement angle index and bearing shear deformation index. The seismic damage prediction matrices of the piers and bearings are listed in Tables 10and 11, respectively. In addition, the calculation results show that the relative displacement of the beam pier at the expansion joint does not exceed the effective support length specified in the code.

The overall damage condition of the bridge structure was identified based on the damage assessment of the key components. The overall seismic damage prediction matrix of the bridge structure obtained from Table 7 is presented in Table 12 . To verify the reliability of the results, the seismic damage prediction matrix of the bridge structure obtained from reference [27] is listed in Table 13.

The bridge seismic damage prediction matrices obtained by the two methods are completely consistent, which shows that the bridge seismic safety evaluation method established in this study is reliable and effective.
TABLE 10: Seismic damage prediction matrix of the bridge pier.

\begin{tabular}{lcccccc}
\hline $\begin{array}{l}\text { Earthquake intensity } \\
\text { Earthquake damage }\end{array}$ & \multicolumn{2}{c}{7} & \multicolumn{2}{c}{8} & \multicolumn{2}{c}{9} \\
grade & $\mathrm{E} 1$ & $\mathrm{E} 2$ & $\mathrm{E} 1$ & $\mathrm{E} 2$ & $\mathrm{E} 1$ & $\mathrm{E} 2$ \\
\hline Basically intact & $100 \%$ & $28.6 \%$ & $41.9 \%$ & 0 & 0 & 0 \\
Slight damage & 0 & 0 & $58.1 \%$ & $28.6 \%$ & $28.6 \%$ & 0 \\
Medium damage & 0 & $71.4 \%$ & 0 & 0 & $58.1 \%$ & $28.6 \%$ \\
Severe damage & 0 & 0 & 0 & 0 & $14.3 \%$ & 0 \\
Destruction & 0 & 0 & 0 & $71.4 \%$ & 0 & $71.4 \%$ \\
\hline
\end{tabular}

TABle 11: Seismic damage prediction matrix of bridge bearing.

\begin{tabular}{lccccccc}
\hline $\begin{array}{l}\text { Earthquake intensity } \\
\text { Earthquake damage }\end{array}$ & \multicolumn{2}{c}{7} & \multicolumn{2}{c}{8} & & \\
grade & E1 & E2 & E1 & E2 & E1 & E2 \\
\hline Basically intact & $85.7 \%$ & 0 & 0 & 0 & 0 & 0 \\
Slight damage & $14.3 \%$ & $28.6 \%$ & $28.6 \%$ & 0 & $14.3 \%$ & 0 \\
Medium damage & 0 & 0 & 0 & 0 & $14.3 \%$ & 0 \\
Severe damage & 0 & $28.6 \%$ & $71.4 \%$ & 0 & 0 & 0 \\
Destruction & 0 & $41.9 \%$ & 0 & $100 \%$ & $71.4 \%$ & $100 \%$ \\
\hline
\end{tabular}

TABle 12: Seismic damage prediction matrix of the bridge (according to Table 7).

Earthquake intensity

\begin{tabular}{lcccccc} 
Earthquake damage grade & \multicolumn{2}{c}{7} & \multicolumn{2}{c}{8} & \\
& E1 & E2 & E1 & E2 & E1 & E2 \\
\hline Basically intact & 1 & 0 & 0 & 0 & 0 & 0 \\
Slight damage & 0 & 0 & 1 & 0 & 0 & 0 \\
Medium damage & 0 & 1 & 0 & 0 & 1 & 0 \\
Severe damage & 0 & 0 & 0 & 0 & 0 & 0 \\
Destruction & 0 & 0 & 0 & 1 & 0 & 1 \\
\hline
\end{tabular}

Table 13: Seismic damage prediction matrix of the bridge (according to reference [27]).

\begin{tabular}{|c|c|c|c|c|c|c|}
\hline \multicolumn{7}{|l|}{ Earthquake intensity } \\
\hline \multirow{2}{*}{ Earthquake damage grade } & \multicolumn{2}{|c|}{7} & \multicolumn{2}{|c|}{8} & \multicolumn{2}{|c|}{9} \\
\hline & E1 & E2 & E1 & $\mathrm{E} 2$ & E1 & E2 \\
\hline Basically intact & 1 & 0 & 0 & 0 & 0 & 0 \\
\hline Slight damage & 0 & 0 & 1 & 0 & 0 & 0 \\
\hline Medium damage & 0 & 1 & 0 & 0 & 1 & 0 \\
\hline Severe damage & 0 & 0 & 0 & 0 & 0 & 0 \\
\hline Destruction & 0 & 0 & 0 & 1 & 0 & 1 \\
\hline
\end{tabular}




\section{Conclusion}

In this study, a two-stage evaluation method for the seismic safety of reinforced concrete beam bridges on expressways in high seismic intensity areas of China was established. The main conclusions are as follows.

(1) Bearing damage, pier damage, and abutment damage are highly correlated with damage to other components. Considering that the abutment and pier structures of expressway bridges are relatively consistent, in this study, we selected bearings and piers as two key components to be used in seismic safety evaluations of concrete beam bridges.

(2) The dimensionless displacement angle of the pier top and shear deformation was selected as the evaluation indexes of the damage state of the pier and bearing, respectively. The calculations are simple, the engineering applicability is strong, and the results closely match the existing specifications. The evaluation index values of different damage states (basically intact, slight damage, medium damage, serious damage, and damage) are given.

(3) A two-stage evaluation method was established. In the first stage, an empirical statistical method was selected to provide evaluation results according to the specific information of the bridge. In the second stage, the damage state of the key components was evaluated according to the structural response. The overall damage state of the bridge structure was determined by the damage state of the key components, and the earthquake damage prediction matrix was given.

(4) By considering the bridge span number, service age, and skew angle affecting the seismic performance of the bridge, the seismic safety evaluation of a typical single bridge is transformed into a seismic safety evaluation of a group of the same type of bridge.

(5) The two-stage bridge seismic safety evaluation method not only solves the problem of evaluation effectiveness but also solves the problem of evaluation efficiency.

\section{Data Availability}

The (displacement angle of pier top) data used to support the findings of this study are included within the article.

\section{Conflicts of Interest}

The authors declare that they have no conflicts of interest.

\section{Acknowledgments}

Financial support by the National Natural Science Foundation of China (Grant nos. 51878347 and 51308293) and the Postgraduate Research and Practice Innovation Program of Jiangsu Province (Grant no. KYCX20_1083) is much appreciated.

\section{References}

[1] X. Wu, W. Guo, P. Hu, D. Bu, X. Xie, and Y. Hu, "Seismic performance evaluation of building-damper system under near-fault earthquake," Shock and Vibration, vol. 2020, Article ID 2763709, 21 pages, 2020.

[2] J. Ge and M. Saiid Saiidi, "Seismic response of the three-span bridge with innovative materials including fault-rupture effect," Shock and Vibration, vol. 2018, Article ID 4276167, 18 pages, 2018.

[3] D. Di Giacinto, P. Malangone, and F. Rizzo, "Seismic retrofit of a multispan prestressed concrete girder bridge with friction pendulum devices," Shock and Vibration, vol. 2018, Article ID 5679480, 22 pages, 2018.

[4] P. Sun, F. Cui, H. Qin, and X. Hou, "Study on regular inspection frequency of bridge based on seismic vulnerability analysis," Shock and Vibration, vol. 2018, Article ID 7157038, 11 pages, 2018.

[5] K. Kubo, "Earthquake damage prediction of bridges," Earthquake Engineering Abroad, vol. 5, pp. 1-11, 1984.

[6] V. Kilar and P. Fajfar, "Simplified push-over analysis of building structures," Proceedings of the 11th World Conference on Earthquake Engineering, vol. 1011, 1996.

[7] A. Ghobarah, H. Abou-Elfath, and A. Biddah, "Responsebased damage assessment of structures," Earthquake Engineering \& Structural Dynamics, vol. 28, no. 1, pp. 79-104, 1999.

[8] B. Gupta and S. K. Kunnath, "Adaptive spectra-based pushover procedure for seismic evaluation of structures," Earthquake Spectra, vol. 16, no. 2, pp. 367-391, 2000.

[9] D. E. Lehman and J. P. Moehle, "Performance-based seismic design of reinforced concrete bridge columns," in Proceedings of the 10th World Earthquake Engineering Conference, New Zealand, March 2000.

[10] I. G. Buckle and S. H. Kim, A Vulnerability Assessment Model for Highway Bridges, Lifeline Earthquake Engineering ASCE, USA, 2014.

[11] Z. Meizhen, "A practical method for predicting seismic damage of highway bridges," Journal of Tongji University, vol. 22, no. 3, pp. 279-283, 1994.

[12] Q-min and Feng, "Seismic damage assessment methods for bridges," Journal of Natural Disasters, vol. 3, pp. 113-118, 2001, (in Chinese).

[13] X. Zhu and J. Q. Gong, "Research and development of seismic design for ductility of reinforced concrete bridge," Bridge Construction, vol. 1, pp. 1-5, 2000, (in Chinese).

[14] L. Pan, Seismic Damage Analysis and Performance Design of Bridge Structures Based on the Method of Overturning Analysis, Tongji University, Shanghai, China, 2001.

[15] J. Shen, M.-H. Tsai, K.-C. Chang, and G. C. Lee, "Performance of a seismically isolated bridge under near-fault earthquake ground motions," Journal of Structural Engineering, vol. 130, no. 6, pp. 861-868, 2004.

[16] J. Deng, T. Liu, W. Xie, and W. Lu, "Study on repaired earthquake-damaged bridge piers under seismic load," Advances in Materials Science and Engineering, vol. 2015, Article ID 295392, 10 pages, 2015.

[17] H. Li, W. Luo, and J. Luo, "Seismic performance of steel box bridge piers with earthquake-resilient function," Advances in Civil Engineering, vol. 2020, Article ID 8877785, 24 pages, 2020.

[18] Y. Liang, Y. Cui, and C. Ren, "Seismic vulnerability analysis of multispan continuous bridges subjected to mainshock- 
aftershock earthquake sequences," Advances in Civil Engineering, vol. 2020, Article ID 7483850, 15 pages, 2020.

[19] M. O. Martineau, A. F. Lopez, and J. C. Vielma, "Effect of earthquake ground motion duration on the seismic response of a low-rise RC building," Advances in Civil Engineering, vol. 2020, Article ID 8891282, 12 pages, 2020.

[20] Z. R. Wang, Study on Gradation Criterion of Seismic Damage and Seismic Behavior of Girder Overpasses, Institute of Engineering Mechanics, China Earthquake Administration, Langfang, China, 2010.

[21] D. H. Tavares, J. E. Padgett, and P. Paultre, "Fragility curves of typical as-built highway bridges in eastern Canada," Engineering Structures, vol. 40, pp. 107-118, 2012.

[22] JTG/T B02-01-2008, Guidelines for Seismic Design of Highway Bridges, China Communications Press, Beijing, China, 2008.

[23] D. H. Yael and F. Seible, "Performance Evaluation Database for Concrete Bridge Components and Systems under Simulated Seismic Loads," Earthquake Engineering Research, vol. 16, no. 2, pp. 413-433, 2000.

[24] Z. Wu and S. Liu, "Seismic fragility analysis of highway bridges considering multi-dimensional performance limit state," Earthquake Engineering and Engineering Vibration, vol. 11, no. 2, pp. 185-193, 2012.

[25] G. Sun, B. Wu, and H. Li, "Study on seismic damage index of displacement angle of reinforced concrete circular bridge pier considering axial compression ratio influence," Journal of Nanjing Tech University (Natural science edition), vol. 42, no. 3, pp. 302-311, 2020.

[26] L. B. Chen, H. Ma, K. Zheng, and W. Zhuang, "Analytical investigation of bridge seismic vulnerability in Wenchuan earthquake," Journal of Southwest Jiaotong University, vol. 47, no. 4, pp. 558-566, 2012.

[27] J. Zhang and Y. Huo, "Evaluating effectiveness and optimum design of isolation devices for highway bridges using the fragility function method," Engineering Structures, vol. 31, no. 8, pp. 1648-1660, 2009.

[28] Z. Zhao, Study on Methodologies for Seismic Estimation of Beam Bridges, Institute of Engineering Mechanics, Harbin, China, 2011.

[29] Z. Y. Liang, Study on Seismic Design Theory of Irregular Girder Bridges with High Pier, Tongji University, Shanghai, China, 2007.

[30] J. Ghosh and J. E. Padgett, "Aging considerations in the development of time-dependent seismic fragility curves," Journal of Structural Engineering, vol. 136, no. 12, pp. 1497-1511, 2010. 